\title{
Diagnosis of coronary artery abnormalities in Kawasaki disease: recent guidelines and $z$ score systems
}

Sung Hye Kim, MD, PhD

Department of Pediatrics, CHA Bundang Medical Center, CHA University, Seongnam, Korea

Kawasaki disease, an acute systemic vasculitis affecting children, is the leading cause of acquired heart disease in developed countries. This vasculitis has a predilection for the coronary artery, and coronary artery abnormalities are the main criteria for its diagnosis. The diagnosis of coronary abnormalities has historically been based on dichotomous criteria, but recent guidelines have accepted the body surface area-adjusted $z$ score system to define coronary abnormalities and classify coronary artery aneurysms. $Z$ score systems have improved risk classifications of coronary aneurysms and improved correlations with clinical prognosis. However, the discrepancy of calculated $\mathrm{z}$ scores according to the formula has been noticed in the application of the $z$ score system, which is possibly related to the diagnosis of coronary artery abnormalities. This variability was greater in larger coronary aneurysm dimensions. A careful choice of the $z$ score formula and its consistent use is needed in clinical applications.

Keywords: Kawasaki disease, Coronary artery, Guideline, $Z$ score

\section{Key message}

- Kawasaki disease is the leading cause of acquired heart disease among children in the developed countries, and Korea has the second-highest incidence in the world.

- Early diagnosis and proper treatment are imperative to prevent coronary complication, and evaluation of coronary artery abnormalities is fundamental.

- Recent guidelines have adapted $z$ score system for the diagnosis of coronary artery abnormalities in Kawasaki disease.

Applying $z$ score in diagnosis of coronary abnormalities has better correlation with clinical outcomes than absolute cutoff values.

- Calculated $z$ scores could be different according to the $z$ score formula, which might influence the treatment plan.

\section{Introduction}

Kawasaki disease, first described by Dr. Tomisaku Kawasaki in 1967 , is an acute febrile vasculitis of unknown origin that mostly affects children under 5 years of age. ${ }^{1)}$ The incidence of Kawasaki disease is higher among children of Asian ethnicity as evidenced by epidemiological data from Hawaii, ${ }^{2)}$ and Korea has the second-highest incidence after Japan. ${ }^{3-5)}$ In a 2015-2017 nationwide survey in Korea, the overall incidence was 196.9 per 100,000 children younger than 5 years, with a mean age at diagnosis of $33.0 \pm 24.8$ months; $83.5 \%$ of patients were under 5 years of age. ${ }^{5)}$

The systemic inflammation in all medium-sized arteries, multiple organs, and tissues during the acute febrile phase is characteristic of Kawasaki disease, ${ }^{\text {, }}$ which has a predilection for the coronary arteries, leading to coronary artery aneurysm in around $25 \%$ of patients without proper treatment. ${ }^{7)}$ Vasculopathy in Kawasaki disease includes acute self-limiting necrotizing arteries causing saccular aneurysms, subacute/chronic vasculitis, and luminal myofibroblastic proliferation possibly related to progressive arterial stenosis and thrombosis. ${ }^{8)}$ These cardiac sequalae might cause myocardial infarction or sudden death in adulthood as well as in the acute phase. ${ }^{9)}$ In developed countries, Kawasaki disease has been emerging as the leading cause of acquired heart disease, surpassing acute rheumatic fever. ${ }^{10)}$

Several studies of intravenous immunoglobulin (IVIG) in the acute phase have been conducted to reduce the prevalence of coronary artery abnormalities and resulted in a reduction in the incidence of coronary artery aneurysms from $25 \%$ to around $4 \% .{ }^{11-13)}$ Nowadays, a single high dose of IVIG and aspirin are the mainstream first-line acute treatment. ${ }^{14,15)}$ A recent survey in Japan reported the acute cardiovascular complication of 7.9\%, coronary dilation of $5.6 \%$, coronary aneurysm of $0.82 \%$, and giant aneurysm of $0.13 \%,{ }^{4)}$ and Korean nationwide surveys performed between 2015 and 2017 reported coronary artery dilation in $17.1 \%$ and coronary artery aneurysm in $1.7 \% .{ }^{5)}$ Both surveys used dichotomous criteria from by the Japanese Ministry of Health and Welfare for diagnosis of coronary artery abnormalities.

Early diagnosis and proper treatment are imperative to preventing coronary complications, for which the evaluation of coronary artery abnormalities is fundamental. In this article, the

Corresponding author: Sung Hye Kim, MD, PhD. Department of Pediatrics, CHA Bundang Medical Center, CHA University, 59 Yatap-ro, Bundang-gu, Seongnam 13496, Korea

凶 Email: rohetkim@yahoo.co.kr, https://orcid.org/0000-0003-3608-0324

Received: 22 September 2021, Revised: 15 November 2021, Accepted: 25 November 2021

This is an open-access article distributed under the terms of the Creative Commons Attribution Non-Commercial License (http://creativecommons.org/licenses/bync/4.0/) which permits unrestricted non-commercial use, distribution, and reproduction in any medium, provided the original work is properly cited.

Copyright (c) 2022 by The Korean Pediatric Society 
diagnosis of coronary artery abnormalities in Kawasaki disease and adaptation of the $z$ score system are reviewed.

\section{Diagnosis of Kawasaki disease}

Due to a lack of pathognomonic diagnostic tests, the characteristic clinical manifestations of Kawasaki disease have formed the basis of its diagnosis: fever, bilateral nonexudative conjunctivitis, erythema of the lips and oral mucosa, changes in the extremities, rash, and cervical lymphadenopathy.

The main diagnostic criteria of Kawasaki disease are based on the guidelines of the American Heart Association (AHA) in 2017 and the Japanese diagnostic guideline (6th revised edition). ${ }^{14,16,17)}$ These 2 guidelines have similar criteria with few differences. According to the AHA guidelines, the diagnosis of complete Kawasaki disease was based on the presence of fever for more than 5 days and $\geq 4$ of 5 principal clinical features. Meanwhile, in the Japanese guidelines, the count of febrile days is not essential and the redness of the bacille CalmetteGuèrin inoculation can be considered a skin rash, one of its principal clinical features. Additionally, the Japanese guidelines regard fever as among the principal clinical features and define complete Kawasaki disease as the presence of at least 5 of the 6 principal clinical features. Complete Kawasaki disease can also be diagnosed with the presence of 4 principal clinical features after the exclusion of other febrile illnesses, and coronary artery dilation $(z$ score $\geq 2.5$ ), absolute diameter $\geq 3 \mathrm{~mm}(<5$ years old), or $\geq 4 \mathrm{~mm}$ ( $\geq 5$ years old).

However, several patients lack full diagnostic clinical features with persistent unexplained fever and are eventually diagnosed with incomplete Kawasaki disease. The incidence of incomplete Kawasaki disease has increased to 20.6\% in Japan and 44.9\% in Korea in recent reports. ${ }^{5,17)}$ Incomplete Kawasaki disease was previously defined as a febrile status with fewer clinical manifestations and coronary artery abnormalities. ${ }^{18)}$ For patients with few clinical manifestations but in whom Kawasaki disease is suspected, the AHA suggested an algorithm for the diagnosis of incomplete Kawasaki disease in 2004 ${ }^{19)}$ and revised it in the 2017 guideline. ${ }^{14)}$ In patients with persistent unexplained fever $\geq 5$ days and 2 or 3 compatible clinical criteria, incomplete Kawasaki disease should be considered. If inflammatory markers are elevated (C-reactive protein $\geq 3 \mathrm{mg} / \mathrm{dL}$ and/or erythrocyte sedimentation rate $\geq 40 \mathrm{~mm} / \mathrm{hr}$ ) and additional laboratory tests or echocardiographic findings are compatible, incomplete Kawasaki disease can be diagnosed and IVIG treatment should be administered. In this algorithm, the echocardiographic criteria are as follows: positive if any of the following 3 conditions are met: (1) $z$ score $\geq 2.5$ for the left anterior descending coronary artery (LAD) or right coronary artery (RCA); (2) coronary artery aneurysm; (3) $\geq 3$ other suggestive features including decreased left ventricular function, mitral regurgitation, pericardial effusion, or $z$ scores for the LAD or RCA of 2-2.5.

Meanwhile, in the Japanese guideline, ${ }^{16,17}$ incomplete Kawasaki disease is defined as the presence of 3 of 6 principal clinical features with coronary artery dilation with the exclusion of other febrile illnesses or in the case of the presence of 3 or 4 principal clinical features without coronary artery dilation but with features from the list of "other significant clinical features," which includes an elevated hepatic transaminase level early in the course the disease, increased leukocytes in the urine sediment of an infant, thrombocytosis in the convalescent phase, elevated brain natriuretic peptide (BNP) or NT-pro BNP level, mitral valve regurgitation or pericardial effusion on echocardiography, enlargement of the gallbladder (hydrops of gall bladder), or hypoalbuminemia or hyponatremia. Incomplete Kawasaki disease may be considered in the presence of $\leq 2$ principal clinical features after the exclusion of other diagnoses. In both guidelines, coronary artery abnormalities are crucial criteria for the diagnosis of complete or incomplete Kawasaki disease.

\section{Evaluation of coronary artery abnormalities in Kawasaki disease}

Echocardiography has been the primary imaging modality for assessing coronary artery abnormalities in Kawasaki disease. A standard image should be obtained for coronary artery diameter measurement with the highest-frequency transducer at the minimum gain setting. The 2-dimensional echocardiographic imaging of the left main coronary artery (LMCA), LAD, left circumflex artery (LCX), and RCA on multiple imaging planes and transducer positions are required for optimal visualization (Fig. 1). ${ }^{20-22)}$ AHA guideline recommends that the initial echocardiogram be performed as soon as possible to ensure proper diagnosis and treatment. ${ }^{14)}$ Dominguez et al. ${ }^{23)}$ reported the importance of the initial echocardiography within the first week of illness. In this study, $81 \%$ of coronary artery abnormalities in patients with Kawasaki disease were identified on the initial echocardiography.

In the early period, coronary artery dilation was defined based on the coronary artery size by the Japanese Ministry of Health and Welfare (Research Committee on Kawasaki Disease, Subcommittee on Standardization of Diagnostic Criteria and Reporting of Coronary Artery Lesions in Kawasaki Disease). ${ }^{24)}$ Dilated lesions were defined as any coronary artery internal lumen diameter greater than $3 \mathrm{~mm}$ for children $<5$ years of age and $4 \mathrm{~mm}$ for those $\geq 5$ years of age. It also included a lesion 1.5 times the diameter of an adjacent normal segment. Additionally, the Japanese Circulation Society classified coronary aneurysms based on absolute diameters as follows: (1) small aneurysm or dilatation: an internal luminal diameter $\leq 4 \mathrm{~mm}$, or in children $\geq 5$ years of age, lesions with an internal diameter $<1.5 \times$ that of an adjacent segment; (2) medium aneurysm: the internal luminal diameter $>4 \mathrm{~mm}$ and $<8 \mathrm{~mm}$, or in children $\geq 5$ years of age, lesions with an internal diameter $1.5-4 \times$ that of an adjacent segment; (3) giant aneurysm: internal luminal diameter $\geq 8 \mathrm{~mm}$, or in children $\geq 5$ years of age, lesions with an internal 

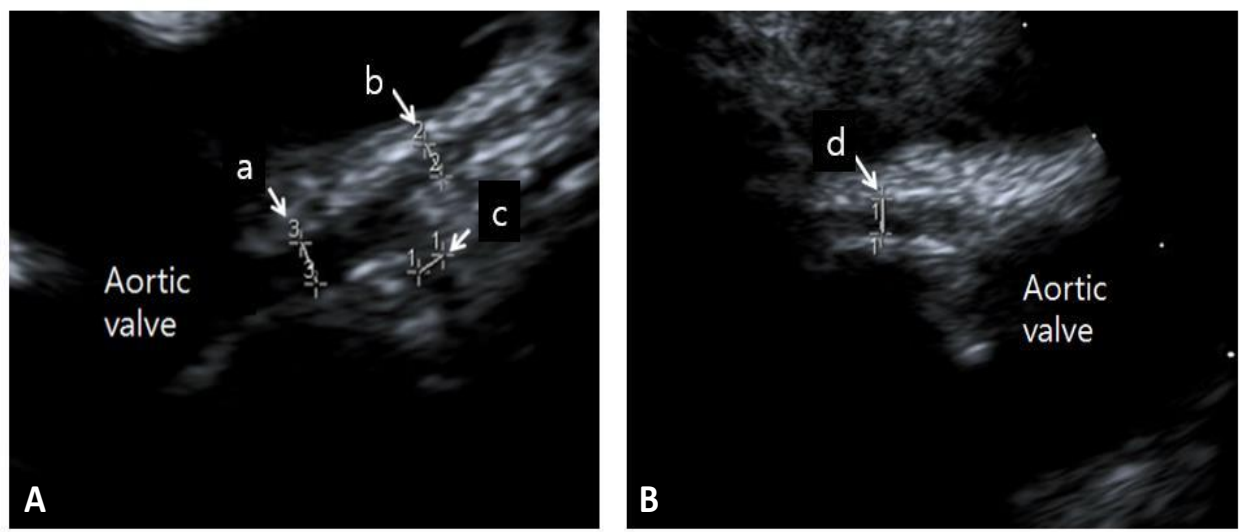

Fig. 1. Standard 2-dimensional echocardiographic image of the coronary arteries (parasternal short axis view). (A) a, left main coronary artery; b, left anterior descending artery; c, left circumflex artery; (B) d, right coronary artery.

diameter $>4 \times$ that of an adjacent segment. ${ }^{25)}$ These arbitrary dichotomous criteria were defined based on clinical experience and have been widely accepted worldwide.

However, concern has persisted that the absolute cutoff criteria might underestimate subtle changes to the coronary arteries and result in misclassification of the coronary artery abnormalities in Kawasaki disease, as these criteria could not account for patient size. ${ }^{26-31)}$ Mean body surface area (BSA)adjusted dimensions of proximal LAD and RCA in patients with normal coronary arteries by the Japanese Ministry Health and Welfare criteria (JMH criteria) were significantly larger than those of normal subjects during a 1-year follow-up period; among them, $27 \%$ had at least one coronary artery with a $\geq 2$ standard deviation (SD) BSA-adjusted coronary dimensions. ${ }^{26}$ ) Similarly, patients without any coronary artery abnormalities by JMH criteria showed increased coronary artery diameters at admission and at 2-3 weeks compared to the normal groups in another study. ${ }^{27)}$ Particularly, in the initial measurements, JMH criteria underestimated the prevalence of coronary abnormalities compared to that defined by BSA-adjusted $\mathrm{z}$ score $(11 \%$ vs. $23 \%){ }^{28)}$ Moreover, Manlhiot et al. ${ }^{29)}$ reported that the aneurysm classification by JCS criteria could underestimated the coronary artery aneurysm severity of $19 \%-32 \%$ of small aneurysms and $35 \%-78 \%$ of medium aneurysms. They suggested the classification using a $z$ score system, which could discriminate coronary artery aneurysms more efficiently and show better correlations with clinical outcomes.

Recent guidelines have accepted the BSA-adjusted $z$ score system for the diagnosis of coronary abnormalities. The 2004 AHA guideline adapted the $z$ score system as one of the definitions of coronary abnormalities for the diagnosis of incom. plete Kawasaki disease as described above. ${ }^{19)}$ The recently revised 2017 AHA guideline updated the definition of coronary abnormalities and the aneurysm classification by the $z$ score system. ${ }^{14)}$ They defined small aneurysms as those with a $z$ score of $\geq 2.5$ to $<5.0$, medium aneurysms as those with a $z$ score of $\geq 5$ to $<10$ and an absolute dimension $<8 \mathrm{~mm}$, and large or giant aneurysms as those with a $z$ score of $\geq 10$ or absolute dimension $\geq 8 \mathrm{~mm}$ (Table 1). The recent Japanese guidelines also adopted the $z$ score system for the classification of coronary artery abnormalities. ${ }^{17)}$ In this guideline, coronary dilation is defined as a $z$ score of internal coronary artery diameter $\geq 2.5$ SD units or absolute diameter $\geq 3 \mathrm{~mm}$ ( $<5$ years old) or $\geq 4 \mathrm{~mm}$ ( $\geq 5$ years old) and coronary artery lesions in the acute phase are defined using both $z$ score and absolute values (Table 1).

\section{Development of $z$ score formulas}

Several BSA-adjusted $z$ score formulas for coronary arteries have been established using various regression methods (Table 2). The Boston $z$ score system for the LMCA, LAD, and RCA derived from 89 healthy subjects by de Zorzi et al. ${ }^{26)}$ was initially generated to evaluate its clinical utility in patients with Kawasaki disease. Since then, more subjects were incorporated by report without the publication of its evolving formula, and this updated Boston $z$ score system has been widely used in North America. ${ }^{32-35)}$ McCrindle et al. ${ }^{36}$ ) derived the $z$ score formula for the LMCA, proximal LAD, and proximal RCA derived from 221 healthy children aged $0-18$ years using exponential regression method and evaluated the changes in the coronary arteries that occur in Kawasaki disease patients. Olivieri et al. ${ }^{37)}$ used a logarithmic regression model and suggested $z$ scores for the LMCA, LAD, and RCA from 432 normal echocardiograms of normal subjects aged 0-20 years. Dallaire and Dahdah ${ }^{38)}$ established $\mathrm{z}$ scores for the LMCA, LAD, LCX, and the proximal, mid, and distal RCA using regression with the square root of BSA from data of 1,033 children. Kobayashi et al. ${ }^{39)}$ used the lambda-mu-sigma method to develop a $z$ score model. They collected 3,851 healthy children $\leq 18$ years of age and established sex-specific $z$ scores for the LMCA, proximal LAD, proximal LCX, and proximal RCA. They also created a Microsoft Excel-based $z$ score calculator (http://raise.umin.jp/ zsp/calculator/). Lopez et al. ${ }^{40)}$ also recently established a z score using the data of 3,566 healthy, diverse, and nonobese children at 19 centers in North America, which was represented by The 
Table 1. Classification of coronary abnormalities in American Heart Association and Japanese Circulation Society guidelines

\begin{tabular}{|c|c|}
\hline Guideline & Classification of coronary abnormalities \\
\hline \multirow[t]{5}{*}{ American Heart Association guideline ${ }^{14)}$} & 1. No involvement: Always $z$ score $<2$ \\
\hline & 2. Dilation only: 2 to $<2.5$; or if initially $<2$, a decrease in $z$ score during follow-up $\geq 1$ \\
\hline & 3. Small aneurysm: $\geq 2.5$ to $<5$ \\
\hline & 4. Medium aneurysm: $\geq 5$ to $<10$, and absolute dimension $<8 \mathrm{~mm}$ \\
\hline & 5. Large or giant aneurysm: $\geq 10$, or absolute dimension $\geq 8 \mathrm{~mm}$ \\
\hline \multicolumn{2}{|l|}{ Japanese Circulation Society guideline $e^{17)}$} \\
\hline \multirow[t]{11}{*}{ Acute phase (<30 days) } & 1. Small aneurysm: $z$ score $\geq 2.5$ to $<5$ \\
\hline & 2. Medium aneurysm: $\geq 5$ to $<10$ \\
\hline & 3. Giant aneurysm: $\geq 10$ \\
\hline & Notes \\
\hline & $\begin{array}{l}\text { (1) If it is difficult to evaluate by } z \text { score, evaluating by absolute value of inner diameter may be used in patients } \\
\text { under } 5 \text { years old }\end{array}$ \\
\hline & - Small aneurysm: $3 \mathrm{~mm} \leq$ inner diameter $<4 \mathrm{~mm}$ \\
\hline & - Medium aneurysm: $4 \mathrm{~mm} \leq$ inner diameter $<8 \mathrm{~mm}$ \\
\hline & - Giant aneurysm: 8 mm $\leq$ inner diameter \\
\hline & $\begin{array}{l}\text { Evaluation by } z \text { score is strongly recommended for age } 5 \text { years and older. (It is overestimated if defined by } \\
\text { absolute value.) }\end{array}$ \\
\hline & - The absolute value of a giant aneurysm is defined as an inner diameter $\geq 8 \mathrm{~mm}$ even at age 5 or older. \\
\hline & $\begin{array}{l}\text { (2) Even if the definition of an aneurysm is satisfied during the course, if it does not fulfil the definition of an } \\
\text { aneurysm at the onset of } 1 \text { month, it will be defined as 'transient dilation' }\end{array}$ \\
\hline \multirow[t]{7}{*}{ Severity classification after 1 month } & 1. No dilation change: no change in the dilation of coronary arteries including the acute phase \\
\hline & 2. Transient dilation (in the acute phase): mild transient dilation that normalizes by 1 month after onset \\
\hline & $\begin{array}{l}\text { 3. Regression: complicated with coronary artery lesion beyond } 1 \text { month from onset, and bilateral coronary } \\
\text { artery findings completely normalize during follow-up, and did not fall into group } 5\end{array}$ \\
\hline & $\begin{array}{l}\text { 4. Remaining coronary aneurysms: coronary aneurysms on one or both sides on coronary angiography but do } \\
\text { not fall into group } 5\end{array}$ \\
\hline & 5. Coronary artery stenotic lesion: coronary angiography shows a stenotic lesion in the coronary artery. \\
\hline & (1) Without ischemic findings in various tests \\
\hline & (2) With ischemic findings in various tests \\
\hline
\end{tabular}

Table 2. $Z$ score formulas for the coronary arteries

\begin{tabular}{|c|c|c|c|c|c|c|}
\hline Study & Year of publication & No. of subjects & $\begin{array}{l}\text { Country of } \\
\text { populations }\end{array}$ & $\begin{array}{l}\text { BSA calculation } \\
\text { method }\end{array}$ & Regression method & $\begin{array}{l}\text { Values for left } \\
\text { circumflex artery }\end{array}$ \\
\hline De Zorzi et al. ${ }^{26)}$ & 1998 & 89 & USA & Not stated & Linear & No \\
\hline McCrindle et al. ${ }^{36)}$ & 2007 & 221 & USA & Haycock & Exponential & No \\
\hline Olivieri et al. ${ }^{37)}$ & 2009 & 432 & USA & DuBois & Logarithmic & No \\
\hline Dallaire and Dahdah'38) & 2011 & 1,036 & Canada & Haycock & Square root & Yes \\
\hline Kobayashi et al. ${ }^{39)}$ & 2016 & 3,851 & Japan & Haycock & The lambda-mu-sigma & Yes \\
\hline Lopez et al. ${ }^{40)}$ & 2017 & 3,566 & North America & Haycock & Exponential & No \\
\hline
\end{tabular}

AHA, American Heart Association; BSA, body surface area; USA, United States of America.

Pediatric Heart Network Investigators. Using exponential regression, they provided $z$ scores for the LMCA, LAD, and proximal RCA that were well correlated with the Boston $z$ score. ${ }^{33)}$ The regression equations and $\mathrm{a} z$ score calculator are also available on the Pediatric Heart Network website (https://www. pediatricheartnetwork.org/z-scores-calculator/). All of these formulas were normalized to BSA. BSA was calculated using the DuBois formula for Olivieri $z$ scores and Haycock formula for the rest except Boston $z$ score. The data from North American population were used in the Boston, McCrindle, Olivieri, Dallaire, and Lopez $z$ score systems and the Japanese population in the Kobayashi $z$ score system. There are also several other $z$ score formulas published in Asia. ${ }^{27,41)}$

\section{Clinical application of $z$ score}

In addition to the diagnosis of Kawasaki disease, a longterm treatment plan was established based on the $z$ score system. In the 2017 AHA guideline, long-term assessment and counseling and long-term thromboprophylaxis such as lowdose aspirin, anticoagulation, and dual antiplatelet therapy is recommended according to the risk classification of coronary artery abnormalities based on the $z$ score system. ${ }^{14)}$ Patients 
with coronary artery dilation only $(z$ score 2 to $<2.5)$ are recommended low-dose aspirin for 6-8 weeks (class IIa; level of evidence, $\mathrm{C}$ ). If luminal dimensions have returned to normal by 4-6 weeks after onset, the patient may be discharged from cardiology care considering a follow-up period of 12 months (class IIa; level of evidence, C). Patients with current or persistent large and giant aneurysms $(z \geq 10$ or absolute dimension $\geq 8$ $\mathrm{mm}$ ) are recommended combined thromboprophylaxis (lowdose aspirin [class I; level of evidence, C] + warfarin [class IIa; level of evidence, B] or low-molecular-weight heparin [class IIa; level of evidence, C]) with cardiologic assessments including echocardiography and electrocardiography at 1, 2, 3, 6, 9, and 12 months after the episode of acute Kawasaki disease in the first year and every 3-6 months thereafter (class IIa; level of evidence, C) (Table 3).

Meanwhile, Japanese guidelines recommend echocardiography or electrocardiography at 1,2, 6, 12 months, and 5 years (or yearly) until 5 years of age for patients with no or transient dilation. Patients with remaining giant aneurysms are recommended to undergo these exams every 6-12 months. Lowdose aspirin is recommended for 2-3 months after onset (class I; level of evidence, C) and should be continued for patients with persistent coronary artery aneurysm (class I; level of evidence, C). Antiplatelet drugs such as clopidogrel, ticlopidine, and dipyridamole are used in combination with low-dose aspirin for patients with medium or large coronary artery aneurysms (class IIa; level of evidence, C), and warfarin is used in combination with low-dose aspirin for patients with large coronary artery aneurysm, a history of myocardial infarction, and thrombosis in the coronary artery aneurysm with an international normalized ratio of prothrombin time target range of 2-2.5 (class Ila; level of evidence, $\mathrm{C}$ ).

Further detailed descriptions of long-term treatment and follow-up plans according to coronary aneurysm classification are easily accessed in both guidelines. ${ }^{14,17)}$

\section{Prognosis of coronary artery abnormalities according to $z$ score classification}

The initial coronary $z$ score and the difference between the initial and follow-up $z$ scores could be possible predictors of subsequent coronary artery abnormalities. ${ }^{42)}$ Also, the diagnosis using $z$ score classification was well correlated and predictive of outcomes, especially in patients with giant aneurysms ( $z$ score $\geq 10) .{ }^{43,44)}$ In an international study of 34 institutions, patients with a $z$ score $<10$ did not show luminal narrowing, thrombosis, or major adverse cardiovascular complications. About $99 \%$ of patients with small $(2.5 \leq z$ score $<5)$, 92\% with medium $(5 \leq z<10)$, and $57 \%$ with large $(z \geq 10)$ coronary aneurysms showed normalized luminal diameters at 10 -year follow-up. ${ }^{44)}$ Another 15-year follow-up study showed that the maximum internal diameter of the coronary artery at 2 months after onset had a strong relationship with following changes in the late

Table 3. Long-term treatment plan according to $z$ score system modified from the 2017 American Heart Association guideline ${ }^{14)}$

\begin{tabular}{|c|c|c|c|c|c|}
\hline Risk level & $\begin{array}{l}\text { Frequency of cardiology } \\
\text { assessment }\end{array}$ & $\begin{array}{c}\text { Assessment for } \\
\text { inducible myocardial } \\
\text { ischemiab) }\end{array}$ & $\begin{array}{l}\text { Low-dose } \\
\text { aspirin }\end{array}$ & $\begin{array}{l}\text { Anticoagulation } \\
\text { (warfarin or low- } \\
\text { molecular-weight } \\
\text { heparin) }\end{array}$ & $\begin{array}{l}\text { Dual antiplatelet therapy } \\
\text { (aspirin + clopidogrel) }\end{array}$ \\
\hline No involvement & $\begin{array}{l}\text { May discharge between } 4 \mathrm{wk} \\
\text { and } 12 \mathrm{mo}\end{array}$ & None & $\begin{array}{l}\text { 4-6 wk then dis- } \\
\text { continue }\end{array}$ & Not indicated & Not indicated \\
\hline Dilation only & $\begin{array}{l}\text { If decreased to normal, dis- } \\
\text { charge between } 4 \text { wk to } 12 \\
\text { mo; if persistent dilation, } \\
\text { reassess every } 2-5 \mathrm{yr}\end{array}$ & None & $\begin{array}{l}\text { Indicated until re- } \\
\text { gression to nor- } \\
\text { mal }\end{array}$ & Not indicated & Not indicated \\
\hline Small aneurysm, current or persistent & Assess at 6 mo, then yearly & Assess every 2-3 yr & indicated & Not indicated & Not indicated \\
\hline $\begin{array}{l}\text { Small aneurysm, regressed to normal } \\
\text { to dilation only }\end{array}$ & $\begin{array}{l}\text { Assess every 1-3 yr (may } \\
\text { omit echocardiography) }\end{array}$ & Assess every $3-5 \mathrm{yr}$ & May be considered & Not indicated & Not indicated \\
\hline $\begin{array}{l}\text { Medium aneurysm, current or persis- } \\
\text { tent }\end{array}$ & $\begin{array}{l}\text { Assess at 3, 6, and } 12 \mathrm{mo} \text {, } \\
\text { then every 6-12 mo }\end{array}$ & Assess every 1-3 yr & indicated & Not indicated & May be considered \\
\hline $\begin{array}{l}\text { Medium aneurysm, regressed to small } \\
\text { aneurysm }\end{array}$ & Assess yearly & Assess every 2-3 yr & indicated & Not indicated & May be considered \\
\hline $\begin{array}{l}\text { Medium aneurysm, regressed to nor- } \\
\text { mal or dilation only }\end{array}$ & $\begin{array}{l}\text { Assess every 1-2 yr (may } \\
\text { omit echocardiography) }\end{array}$ & Assess every $2-5 \mathrm{yr}$ & $\begin{array}{l}\text { Reasonably indi- } \\
\text { cated }\end{array}$ & Not indicated & $\begin{array}{l}\text { Not recommended except } \\
\text { in the presence of induci } \\
\text { ble myocardial ischemia }\end{array}$ \\
\hline $\begin{array}{l}\text { Large or giant aneurysm, current or } \\
\text { persistent }\end{array}$ & $\begin{array}{l}\text { Assess at 3, 6, 9, and } 12 \text { mo, } \\
\text { then every 3-6 mo }\end{array}$ & Assess every 6-12 mo & Indicated & $\begin{array}{l}\text { Reasonably in- } \\
\text { dicated }\end{array}$ & $\begin{array}{l}\text { May be considered in addi- } \\
\text { tion to anticoagulation }{ }^{c)}\end{array}$ \\
\hline $\begin{array}{l}\text { Large or giant aneurysms, regressed } \\
\text { to medium aneurysm }\end{array}$ & Assess every 6-12 mo & Assess yearly & Indicated & Not indicated & Reasonably indicated \\
\hline $\begin{array}{l}\text { Large to giant aneurysm, regressed to } \\
\text { small aneurysm }\end{array}$ & Assess every 6-12 mo & Assess every 1-2 yr & Indicated & Not indicated & Not indicated \\
\hline $\begin{array}{l}\text { Large or giant aneurysm, regressed to } \\
\text { normal or dilation only }\end{array}$ & $\begin{array}{l}\text { Assess every 1-2 yr (may } \\
\text { omit echocardiography) }\end{array}$ & Assess every 2-5 yr & $\begin{array}{l}\text { Reasonably indi- } \\
\text { cated }\end{array}$ & Not indicated & Not indicated \\
\hline
\end{tabular}


Table 4. Summary of the results of the recent studies of the prognosis of coronary artery abnormalities according to $z$ score

\begin{tabular}{|c|c|c|c|}
\hline Study & Year & Patient number & Major findings \\
\hline Friedman et al. ${ }^{43)}$ & 2016 & 2,860 & $\begin{array}{l}\text { Coronary artery } z \text { score at diagnosis was highly predictive of outcomes. } \\
\text { Larger } z \text { score }(z \geq 5) \text { was associated with higher maximal coronary artery } z \text { score. }\end{array}$ \\
\hline McCrindle et al. ${ }^{44)}$ & 2020 & 1,651 & Medium-term risk of complications is confined to those with maximum coronary artery $z$ scores $\geq 10$ \\
\hline Suzuki et al. ${ }^{42)}$ & 2021 & 281 & $\begin{array}{l}\text { Pretreatment } z \text { max and difference of } z \text { max between pretreatment and } 4 \text { weeks after onset may } \\
\text { predict of coronary artery lesions. }\end{array}$ \\
\hline Tsuda et al. ${ }^{45)}$ & 2021 & 85 & $\begin{array}{l}\text { Coronary artery aneurysms with a maximum diameter } \geq 6 \mathrm{~mm} \text { and } z \text { score } \geq 7.5 \text { at } 2 \text { months after } \\
\text { Kawasaki disease persisted in adolescents, whereas coronary arteries with diameters }<6 \mathrm{~mm} \text { and } z \\
\text { score }<7.5 \text { could be within normal ranges in the late period. }\end{array}$ \\
\hline
\end{tabular}

Table 5. The variability of calculated $z$ scores according to various $z$ score formulas ${ }^{\text {a) }}$

\begin{tabular}{|c|c|c|c|c|c|c|}
\hline & \multirow{2}{*}{$\begin{array}{c}\text { Absolute value of } \\
\text { LAD }\end{array}$} & \multicolumn{5}{|c|}{$Z$ score formula } \\
\hline & & McCrindle et al. ${ }^{36)}$ & Olivieri et al. ${ }^{37)}$ & Dallaire and Dahdah ${ }^{38)}$ & Kobayashi et al. ${ }^{39)}$ & Lopez et al. ${ }^{40)}$ \\
\hline \multirow{3}{*}{$\begin{array}{l}\text { 2-year-old boy, } 13 \text { kg, } \\
90 \mathrm{~cm}\end{array}$} & $2.5 \mathrm{~mm}$ & 2.57 & 1.93 & 2.71 & 2.22 & 3.85 \\
\hline & $4 \mathrm{~mm}$ & 8.31 & 4.52 & 7.06 & 4.86 & 9.52 \\
\hline & $8 \mathrm{~mm}$ & 23.64 & 8.33 & 18.67 & 8.87 & 24.62 \\
\hline \multirow{3}{*}{$\begin{array}{l}\text { 5-year-old boy, } 19 \text { kg, } \\
110 \mathrm{~cm}\end{array}$} & $3 \mathrm{~mm}$ & 3.11 & 2.30 & 3.16 & 252 & 4.38 \\
\hline & $4 \mathrm{~mm}$ & 6.46 & 3.88 & 5.85 & 4.25 & 7.71 \\
\hline & $8 \mathrm{~mm}$ & 19.86 & 7.69 & 16.63 & 8.81 & 21.00 \\
\hline
\end{tabular}

$L A D$, left anterior descending coronary artery.

a) Using Microsoft Excel-based $z$ score calculator available at: http://raise.umin.jp/zsp/calculator/.

period. ${ }^{45)}$ The coronary aneurysm of maximum diameters $\geq 8$ $\mathrm{mm}$ at 2 months did not show significant changes after 1 year, while the coronary aneurysm $<8 \mathrm{~mm}$ significantly decreased in size and the coronary aneurysm $<6 \mathrm{~mm}$ with a $z$ score $<7.5$ could be normalized in the late period. Table 4 summarizes the results of recent studies. A nationwide survey of patients with coronary aneurysm diameter $>6 \mathrm{~mm}$ in Korea showed a persistent coronary aneurysm in $96 \%$ of them, while $31 \%$ developed coronary stenosis. ${ }^{46}$ However, the $z$ score system was not applied in this study, and a comparative study using a $z$ score system and including a large number of patients is needed to evaluate the prognostic value of the $z$ score system in the Korean population.

\section{Impact of zscores in managing Kawasaki disease}

Although coronary artery aneurysm classification is a better predictor than the absolute diameter criteria, there are some issues with its clinical application. Each $z$ score formula yielded slightly different results, which could influence the diagnosis of coronary artery abnormalities, and the discrepancy of calculated $z$ scores is greater for larger coronary aneurysms. ${ }^{30,31,32,34)}$ For example, an LAD of $2.5 \mathrm{~mm}$ in a 2-year-old boy with a weight of $13 \mathrm{~kg}$ and a height of $90 \mathrm{~cm}$ could be normal on Olivieri's formula but small aneurysm on Lopez's formula, while a z score of an 8-mm LAD in boy with the same BSA could be 8.33-24.62 according to the $z$ score formula (Table 5).

Compared to the range of lower $z$ scores (1.5-3), the range of large $z$ scores (7-14) showed the noticeable discrepancy among the Boston, Olivieri, and Dallaire $z$ score systems. ${ }^{32)} \mathrm{A}$ comparative study using the data of 181 healthy Korean children showed the statistical feasibility of normal distribution among the McCrindle, Oliveri, Dallaire, and Kobayashi $z$ score systems. ${ }^{47)}$ However, Kim et al. ${ }^{31)}$ reported a large nationwide retrospective cross-sectional analysis of 6,889 Korean children with Kawasaki disease in which the choice of guidelines or $z$ score systems could result in different rates of coronary artery abnormalities, and the calculated $z$ scores showed the discrepancies among the $z$ score systems. The $z$ score formula of LAD by Lopez produced the highest $z$ scores, while that by Olivieri produced the lowest $z$ scores among McCrindle, Olivieri, Dallaire, Kobayashi, and Lopez's $z$ scores, and the discrepancy was maximized in the extreme dimension (Fig. 2). In the analysis of the $4 z$ score systems from North America (The Boston, Dallaire, Olivieri, and Lopez $z$ score systems), the acute coronary abnormalities were $24 \%-55 \%$, especially in the LAD. ${ }^{34)}$

Additionally, the choice of $z$ score system influenced the classification of coronary artery aneurysms related to the longterm treatment plan. ${ }^{31,34)}$ Patients with giant aneurysms by Dallaire $z$ scores were diagnosed as having medium aneurysms in $58 \%$ of cases and giant aneurysms in $42 \%$ of cases by the Kobayashi $z$ score in the report by Kim et al. ${ }^{31)}$ Similarly, up to $22 \%$ of Kawasaki patients could have a changed long-term anticoagulation treatment plan due to the differences among the Boston, Dallaire, Olivieri, and Lopez z score systems in the report by Lorenzoni et al. ${ }^{34)}$ They reported that the Dallaire $z$ score system diagnosed the most aneurysms in the LMCA, the Lopez $z$ score system in the $\mathrm{LAD}$, and the Boston system in the RCA.

This discrepancy may be due to various reasons. These BSAadjusted $z$ score systems used different BSA equations and were derived from different normal population sizes, sexes, and 


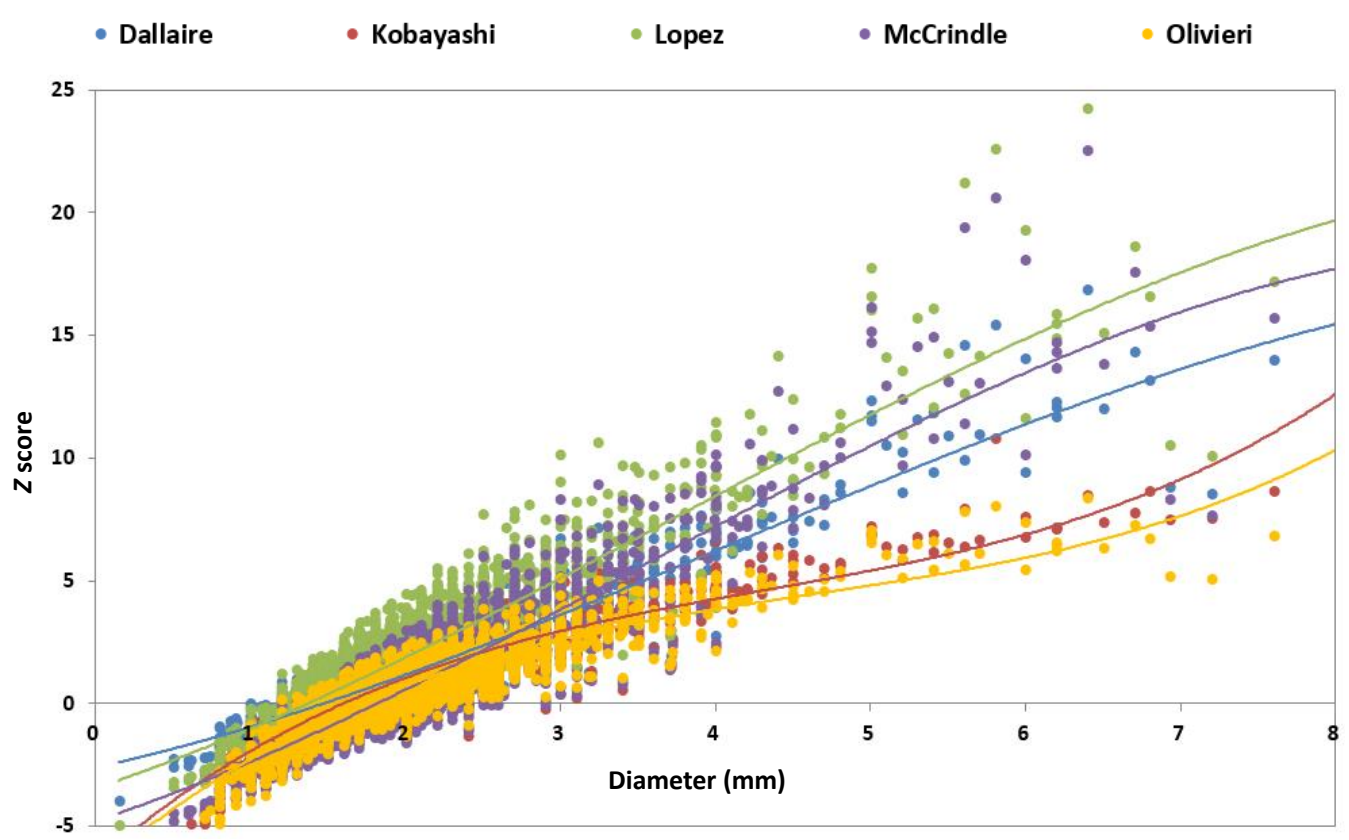

Fig. 2. Correlation between $z$ scores and the inner diameter of the left anterior descending artery. Modified from Kim et al. J Am Soc Echocardiogr 2021;34:662-72. ${ }^{31}$

races. The regression methods also differed according to the $z$ score system. In the report by Kim et al., ${ }^{31)}$ among the $4 z$ score systems using the Haycock equation in the BSA calculation, 3 $z$ score systems from North America yielded higher $z$ scores in every coronary artery than the Kobayashi $z$ score system, which implies a possible ethnic effect of the $z$ score formula.

Because the $z$ score system is strongly related to risk stratification and the long-term treatment plan, the $z$ score formula should be selected carefully and consistently. Until now, there has been no coronary artery $z$ score formula derived from data from a large Korean population. Further research is needed to determine the ideal coronary $z$ score system for this ethnic group and evaluate its prognostic value.

\section{Conclusion}

The diagnosis of coronary artery abnormalities is imperative in Kawasaki disease. The coronary $z$ score system has been widely adapted in the guidelines and clinical field to evaluate coronary abnormalities and classify risk stratification according to coronary aneurysms. The classification of coronary artery aneurysms using the $z$ score system is well correlated with clinical outcomes. The choice of $z$ score formula yields different results, possibly related to the diagnosis of coronary artery abnormalities, and the discrepancy of calculated $z$ scores is greater for the larger coronary aneurysms. A careful choice of $z$ score formula and its consistent use is needed to enable its clinical applications.

See the commentary on "Characteristics of $z$ score systems for diagnosing coronary abnormalities in Kawasaki disease" via https://doi.org/10.3345/cep.2021.01886.

\section{Footnotes}

Conflicts of interest: No potential conflict of interest relevant to this article was reported.

Funding: This study received no specific grant from any funding agency in the public, commercial, or not-for-profit sectors.

ORCID:

Sung Hye Kim @ https://orcid.org/0000-0003-3608-0324

\section{References}

1. Kawasaki T. Acute febrile mucocutaneous syndrome with lymphoid involvement with specific desquamation of the fingers and toes in children. Arerugi 1967;16:178-222.

2. Holman RC, Christensen KY, Belay ED, Steiner CA, Effler PV, Miyamura $\mathrm{J}$, et al. Racial/ethnic differences in the incidence of Kawasaki syndrome among children in Hawaii. Hawaii Med J 2010;69:194-7.

3. Uehara R, Belay ED. Epidemiology of Kawasaki disease in Asia, Europe, and the United States. J Epidemiol 2012;22:79-85.

4. Report of the 24th Nation-wide Survey for Kawasaki Disease (in Japanese) [Internet]. [cited 2019 Mar 31]. Available from: http://www. jichi.ac.jp/dph/kawasakibyou/20170928/mcls24report.pdf.

5. Kim GB, Eun LY, Han JW, Kim SH, Yoon KL, Han MY, et al. Epidemiology of Kawasaki disease in South Korea: a nationwide survey 20152017. Pediatr Infect Dis J 2020;39:1012-6.

6. Amano S, Hazama F, Kubagawa H, Tasaka K, Haebara H, Hamashima Y. General pathology of Kawasaki disease. On the morphological alterations corresponding to the clinical manifestations. Acta Pathol Jpn 1980; 30:681-94.

7. Kato H, Sugimura T, Akagi T, Sato N, Hashino K, Maeno Y, et al. Longterm consequences of Kawasaki disease. A 10- to 21-year follow-up study of 594 patients. Circulation 1996;94:1379-85.

8. Orenstein JM, Shulman ST, Fox LM, Baker SC, Takahashi M, Bhatti 
TR, et al. Three linked vasculopathic processes characterize Kawasaki disease: a light and transmission electron microscopic study. PLoS One 2012;7:e38998.

9. Burns JC, Shike H, Gordon JB, Malhotra A, Schoenwetter M, Kawasaki T. Sequelae of Kawasaki disease in adolescents and young adults. J Am Coll Cardiol 1996;28:253-7.

10. Taubert KA, Rowley AH, Shulman ST. Nationwide survey of Kawasaki disease and acute rheumatic fever. J Pediatr 1991;119:279-82.

11. Furusho K, Kamiya $T$, Nakano $H$, Kiyosawa $N$, Shinomiya $K$, Hayashidera T, et al. High-dose intravenous gammaglobulin for Kawasaki disease. Lancet 1984;2:1055-8.

12. Newburger JW, Takahashi M, Burns JC, Beiser AS, Chung KJ, Duffy CE, et al. The treatment of Kawasaki syndrome with intravenous gamma globulin. NEngl J Med 1986;315:341-7.

13. Newburger JW, Takahashi M, Beiser AS, Burns JC, Bastian J, Chung KJ, et al. A single intravenous infusion of gamma globulin as compared with four infusions in the treatment of acute Kawasaki syndrome. N Engl J Med 1991;324:1633-9.

14. McCrindle BW, Rowley AH, Newburger JW, Burns JC, Bolger AF, Gewitz $\mathrm{M}$, et al. Diagnosis, treatment, and long-term management of Kawasaki disease: a scientific statement for health professionals from the American Heart Association. Circulation 2017;135:e927-99.

15. Research Committee of the Japanese Society of Pediatric Cardiology; Cardiac Surgery Committee for Development of Guidelines for Medical Treatment of Acute Kawasaki Disease. Guidelines for Medical Treatment of Acute Kawasaki Disease: Report of the Research Committee of the Japanese Society of Pediatric Cardiology and Cardiac Surgery (2012 revised version). Pediatr Int 2014;56:135-58.

16. Kobayashi T, Ayusawa M, Suzuki H, Abe J, Ito S, Kato T, et al. Revision of diagnostic guidelines for Kawasaki disease (6th revised edition). Pediatr Int 2020;62:1135-8.

17. Fukazawa R, Kobayashi J, Ayusawa M, Hamada H, Miura M, Mitani Y, et al. JCS/JSCS 2020 guideline on diagnosis and management of cardiovascular sequelae in Kawasaki disease. Circ J 2020;84:1348-407.

18. Dajani AS, Taubert KA, Gerber MA, Shulman ST, Ferrieri P, Freed M, et al. Diagnosis and therapy of Kawasaki disease in children. Circulation 1993;87:1776-80.

19. Newburger JW, Takahashi M, Gerber MA, Gewitz MH, Tani LY, Burns JC, et al. Diagnosis, treatment, and long-term management of Kawasaki disease: a statement for health professionals from the Committee on Rheumatic Fever, Endocarditis, and Kawasaki Disease, Council on Cardiovascular Disease in the Young, American Heart Association. Pediatrics 2004;114:1708-33.

20. Fuse S, Kobayashi T, Arakaki Y, Ogawa S, Katoh H, Sakamoto N, et al. Standard method for ultrasound imaging of coronary artery in children. Pediatr Int 2010;52:876-82.

21. Brown LM, Duffy CE, Mitchell C, Young L. A practical guide to pediatric coronary artery imaging with echocardiography. J Am Soc Echocardiogr 2015;28:379-91.

22. Lopez L, Colan SD, Frommelt PC, Ensing GJ, Kendall K, Younoszai AK, et al. Recommendations for quantification methods during the performance of a pediatric echocardiogram: a report from the Pediatric Measurements Writing Group of the American Society of Echocardiography Pediatric and Congenital Heart Disease Council. J Am Soc Echocardiogr 2010; 23:465-95; quiz 576-7.

23. Dominguez SR, Anderson MS, El-Adawy M, Glodé MP. Preventing coronary artery abnormalities: a need for earlier diagnosis and treatment of Kawasaki disease. Pediatr Infect Dis J 2012;31:1217-20.

24. Kamiya T, Kawasaki T, Okuni M, Kato H, Baba K, Nakano H. Report of subcommittee on standardization of diagnostic criteria and reporting of coronary artery lesions in Kawasaki disease. Research Committee on Kawasaki Disease of the Ministry of Health and Welfare. Tokyo (Japan): Japanese Ministry of Health and Welfare, 1984.

25. JCS Joint Working Group. Guidelines for diagnosis and management of cardiovascular sequelae in Kawasaki disease (JCS 2013). Digest version. Circ J 2014;78:2521-62.

26. de Zorzi A, Colan SD, Gauvreau K, Baker AL, Sundel RP, Newburger JW.
Coronary artery dimensions may be misclassified as normal in Kawasaki disease. J Pediatr 1998;133:254-8.

27. Kurotobi S, Nagai T, Kawakami N, Sano T. Coronary diameter in normal infants, children and patients with Kawasaki disease. Pediatr Int 2002; 44:1-4.

28. Crystal MA, Manlhiot C, Yeung RS, Smallhorn JF, McCrindle BW. Coronary artery dilation after Kawasaki disease for children within the normal range. Int J Cardiol 2009;136:27-32.

29. Manlhiot C, Millar K, Golding F, McCrindle BW. Improved classification of coronary artery abnormalities based only on coronary artery z-scores after Kawasaki disease. Pediatr Cardiol 2010;31:242-9.

30. Liu HH, Qiu Z, Fan GZ, Jiang Q, Li RX, Chen WX, et al. Assessment of coronary artery abnormalities and variability of Z-score calculation in the acute episode of Kawasaki disease-A retrospective study from China. Eur J Clin Invest 2021;51:e13409.

31. Kim SH, Kim JY, Kim GB, Yu JJ, Choi JW. Diagnosis of coronary artery abnormalities in patients with Kawasaki disease according to established guidelines and Z score formulas. J Am Soc Echocardiogr 2021;34:66272.e3.

32. Ronai C, Hamaoka-Okamoto A, Baker AL, de Ferranti SD, Colan SD, Newburger JW, et al. Coronary artery aneurysm measurement and Z score variability in Kawasaki disease. J Am Soc Echocardiogr 2016;29: 150-7.

33. Lopez L, Frommelt PC, Colan SD, Trachtenberg FL, Gongwer R, Stylianou M, et al. Pediatric Heart Network echocardiographic Z scores: comparison with other published models. J Am Soc Echocardiogr 2021; 34:185-92.

34. Lorenzoni RP, Elkins N, Quezada M, Silver EJ, Mahgerefteh J, Hsu DT, et al. Impact of $\mathrm{Z}$ score system on the management of coronary artery lesions in Kawasaki disease. Cardiol Young 2022;32:952-9.

35. Robinson DL, Ware AL, Sauer MC, Williams RV, Ou Z, Presson AP, et al. Implications of changing Z-score models for coronary artery dimensions in Kawasaki disease. Pediatr Cardiol 2021;42:432-41.

36. McCrindle BW, Li JS, Minich LL, Colan SD, Atz AM, Takahashi M, et al. Coronary artery involvement in children with Kawasaki disease: risk factors from analysis of serial normalized measurements. Circulation 2007;116:174-9.

37. Olivieri L, Arling B, Friberg M, Sable C. Coronary artery Z score regression equations and calculators derived from a large heterogeneous population of children undergoing echocardiography. J Am Soc Echocardiogr 2009;22:159-64.

38. Dallaire F, Dahdah N. New equations and a critical appraisal of coronary artery Z scores in healthy children. J Am Soc Echocardiogr 2011;24:6074.

39. Kobayashi T, Fuse S, Sakamoto N, Mikami M, Ogawa S, Hamaoka $\mathrm{K}$, et al. A new $\mathrm{Z}$ score curve of the coronary arterial internal diameter using the lambda-mu-sigma method in a pediatric population. J Am Soc Echocardiogr 2016;29:794-801.e29.

40. Lopez L, Colan S, Stylianou M, Granger S, Trachtenberg F, Frommelt P, et al. Relationship of echocardiographic $\mathrm{Z}$ scores adjusted for body surface area to age, sex, race, and ethnicity: the Pediatric Heart Network Normal Echocardiogram Database. Circ Cardiovasc Imaging 2017;10:e006979.

41. Tan TH, Wong KY, Cheng TK, Heng JT. Coronary normograms and the coronary-aorta index: objective determinants of coronary artery dilatation. Pediatr Cardiol 2003;24:328-35.

42. Suzuki T, Kakimoto N, Tsuchihashi T, Suenaga T, Takeuchi T, Shibuta S, et al. Z-score is a possible predictor of the risk of coronary artery lesion development in patients with Kawasaki disease in Japan. Eur J Pediatr 2021;180:2797-805.

43. Friedman KG, Gauvreau K, Hamaoka-Okamoto A, Tang A, Berry E, Tremoulet AH, et al. Coronary artery aneurysms in Kawasaki disease: risk factors for progressive disease and adverse cardiac events in the US population. J Am Heart Assoc 2016;15;5:e003289.

44. McCrindle BW, Manlhiot C, Newburger JW, Harahsheh AS, Giglia TM, Dallaire F, et al. Medium-term complications associated with coronary artery aneurysms after Kawasaki disease: a study from the International Kawasaki Disease Registry. J Am Heart Assoc 2020;9:e016440. 
45. Tsuda E, Hashimoto S. Changes in coronary aneurysm diameters after acute Kawasaki disease from infancy to adolescence. Pediatr Cardiol 2021;42:1749-56.

46. Jang GY, Kang IS, Choi JY, Bae EJ, Kim YH, Kim SH, et al. Nationwide survey of coronary aneurysms with diameter $>6 \mathrm{~mm}$ in Kawasaki disease in Korea. Pediatr Int 2015;57:367-72.

47. Ryu K, Yu JJ, Jun HO, Shin EJ, Heo YH, Baek JS, et al. A comparative study of established $\mathrm{z}$ score models for coronary artery diameters in 181 healthy Korean children. Korean J Pediatr 2017;60:373-8.
How to cite this article: Kim SH. Diagnosis of coronary artery abnormalities in Kawasaki disease: recent guidelines and $z$ score systems. Clin Exp Pediatr 2022;65:430-8. https:// doi.org/10.3345/cep.2021.01459 